\title{
Review \\ CCAAT/enhancer binding proteins in normal mammary development and breast cancer
}

\author{
Cynthia A Zahnow
}

The Sidney Kimmel Comprehensive Cancer Center at Johns Hopkins, Baltimore, Maryland, USA

Correspondence: Cynthia A Zahnow, The Sidney Kimmel Comprehensive Cancer Center at Johns Hopkins, 1650 Orleans Street, Baltimore, MD 21231, USA. Tel: +1 410955 8506; fax: +1 410614 9884; e-mail zahnoci@jhmi.edu

Received: 20 February 2002

Revisions requested: 25 March 2002

Revisions received: 3 April 2002

Accepted: 3 April 2002

Published: 19 April 2002
Breast Cancer Res 2002, 4:113-121

(C) 2002 BioMed Central Ltd

(Print ISSN 1465-5411; Online ISSN 1465-542X)

\begin{abstract}
CCAAT/enhancer binding proteins (C/EBPs) are a family of leucine zipper, transcription factors that bind to DNA as homodimers and heterodimers. They regulate cellular proliferation, differentiation and apoptosis in the mammary gland. Multiple protein isoforms, including truncated, dominant negatives, are generated by translation of the $C / E B P \beta$ transcript or via proteolytic cleavage of the full-length $\mathrm{C} / \mathrm{EBP} \beta$ protein. Gene deletion of individual C/EBP family members has demonstrated an essential role for $C / E B P \beta$ in normal mammary development, while transgenic and overexpression studies provide evidence that the dominant-negative C/EBP $\beta$-liver-enriched inhibitory protein isoform induces proliferation in mammary epithelial cells. Mounting evidence suggests that alterations in the ratio of the C/EBP $\beta$-liver-enriched inhibitory protein isoform and the C/EBP $\beta$-liver-enriched activating protein isoform may play a role in the development of breast cancer. This review will consequently focus on $\mathrm{C} / \mathrm{EBP}$ actions in normal mammary development and on the emerging data that supports a role in breast cancer.
\end{abstract}

Keywords: breast cancer, CCAAT/enhancer binding proteins, dominant-negative transcription factor, mammary development, translational regulation

\section{Introduction}

Breast cancer is, in part, a result of the overexpression of transcription factors that disrupt the delicate balance between cellular proliferation, terminal differentiation and programmed cell death. Yet, when expressed at physiologic levels, many of these same transcription factors are critical for normal development of the mammary gland. The C/EBPs play a pivotal role in controlling growth and differentiation of the mammary gland. Accordingly, this review focuses on the role that the C/EBPs play in both breast cancer and in normal mammary development.
The C/EBPs together form a highly conserved family of transcription factors that bind to sequence-specific DNA sequences as dimers and that regulate the transcription of genes involved in proliferation and differentiation. Six C/EBP genes have thus far been identified, and they are designated $C / E B P \alpha, C / E B P \beta, \quad C / E B P \gamma, C / E B P \delta, \quad C / E B P \varepsilon$, and $\mathrm{C} / E B P \zeta$ (also known as CHOP [C/EBP homologous protein-10] or $G A D D 153$ ) (for a review of the nomenclature, see [1]). Of these genes, $C / E B P \beta, C / E B P \alpha$, and $C / E B P \delta$ have been the most thoroughly studied in rodent and human mammary tissue, and will be the focus of this review. 


\section{C/EBP $\beta$ mRNA:}

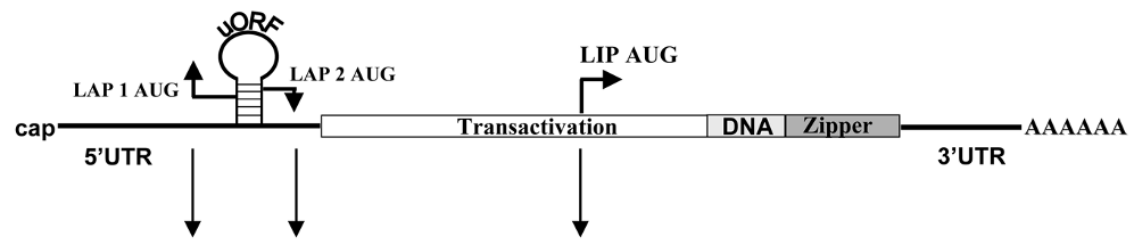

Protein Isoforms:

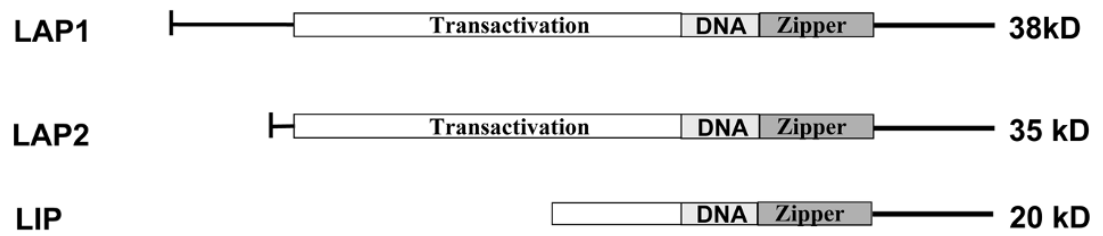

CCAAT/enhancer binding protein beta (C/EBP $\beta) \mathrm{mRNA}$ is translated into multiple protein isoforms. Schematic representation of $C / E B P \beta \mathrm{mRNA}$, its three potential translation start sites and the resultant protein isoforms. The transactivation domain, the DNA binding domain (DNA) and the leucine zipper, dimerization domain (Zipper) are indicated. It has been suggested that the upstream open reading frame (uORF) is located within a stem loop structure, and the LAP translation start sites are shown positioned on either side of the uORF. Alternative isoforms, in addition to those represented in this figure, may be present in other tissues and species. LAP, liver-enriched activating protein; LIP, liver-enriched inhibitory protein; UTR, untranslated region.

C/EBPs belong to the leucine zipper class of DNAbinding proteins. They contain an amino-terminal transactivation domain and a highly basic DNA-binding region immediately adjacent to the carboxyl-terminal, leucine-rich dimerization domain (Fig. 1).

The dimerization domain is characterized as an amphipathic, $\alpha$-helix containing a heptad repeat of leucines that project uniformly along the hydrophobic side of the helix and that interdigitate with the leucine residues of a dimerization partner [2]. Dimerization can occur within a C/EBP family, between different C/EBP family members, or between different groups of leucine zipper proteins [3]. Dimerization of these helices has been proposed to bring into close proximity the basic amino acids associated with the DNA binding domain from the two polypeptide chains $[2,4]$. Dimerization is consequently a prerequisite to DNA binding and, when not bound to DNA, the dimers readily dissociate back to monomers [3].

With the exception of C/EBPE and CHOP, all of the $\mathrm{C} / \mathrm{EBP}$ genes are intronless and transcription results in a single mRNA that is translated to yield multiple protein isoforms. During mammary gland development, $C / E B P \beta$, $C / E B P \alpha$ and $C / E B P \delta$ are differentially and temporally expressed to coordinately control mammary growth, differ-

\section{Expression of C/EBPs during mammary gland development C/EBP $\beta$ gene}

$C / E B P \beta$ is expressed in numerous tissues, including the liver, adipose tissue, the intestine, the ovary, the lung, the mammary gland, skin, the brain, the kidney, the heart and hematopoietic tissues. Transcription of the intronless $C / E B P \beta$ gene results in a single $1.4 \mathrm{~kb}$ mRNA that can be translated via alternative start sites into three isoforms: fulllength, $38 \mathrm{kDa}$ liver-enriched activating protein (LAP) 1 ; $35 \mathrm{kDa}$ LAP2; and $20 \mathrm{kDa}$ liver-enriched inhibitory protein (LIP).

The most abundant and easily detected isoforms in the mouse mammary gland are LAP2 $(35 \mathrm{kDa})$ and LIP $(20 \mathrm{kDa})$. In human breast tissue, the LAP isoforms are larger (approximately $42-46 \mathrm{kDa}$ ) and the LIP isoform remains unchanged at $20 \mathrm{kDa}$. This increase in size of the LAP isoforms is due to an additional 49 amino acid residues located in the $\mathrm{N}$-terminal portion of the human $\mathrm{C} / \mathrm{EBP} \beta$ protein that are excluded from the LIP isoform. A larger LAP isoform $(55 \mathrm{kDa})$ has also been reported in nontransformed, human mammary cells [5].

Both the LAP and LIP isoforms have the same DNA binding and dimerization domains but, due to translation at an alternative downstream start codon, LIP lacks 
much of the trans-activation domain (Fig. 1). LIP is consequently unable to activate gene transcription [6]. As with all C/EBP family members, LAP and LIP are capable of forming homodimers or heterodimers with each other. Also, LIP can antagonize the transcriptional activating potential of LAP by competing for DNA binding sites as a homodimer or by its interaction in a LAP/LIP heterodimer [6]. Because of an increased DNA affinity of the LIP isoform, this inhibition of transcriptional activity can occur even at substoichiometric ratios of LIP/LAP, thereby suggesting a dominant-negative function for LIP [6]. LAP and LIP thus have opposing actions on gene activation, and the LAP/LIP ratio, rather than their absolute amounts, may be an important indicator of $C / E B P \beta$ transcriptional activity.

\section{C/EBP $\beta$ MRNA}

$C / E B P \beta$ mRNA expression levels are detectable in the virgin gland. These expression levels increase during pregnancy, decline during lactation, and increase again during the onset of involution [7].

\section{C/EBP $\beta$ protein}

C/EBP $\beta$-LAP2 is detected in whole cell extracts of the virgin rat gland and is elevated twofold to threefold with the onset of pregnancy. Although LAP levels decrease at parturition, they are readily detectable throughout lactation and involution [8]. The LIP isoform is expressed at very low levels in the virgin gland and is dramatically upregulated (100-fold) during pregnancy [8]. LIP then decreases to nearly undetectable levels at parturition and remains low throughout lactation [8]. Similar protein expression profiles have been observed in the mouse mammary gland [9].

In summary, the C/EBP-LAP isoform, although variable in expression levels, is detectable at all stages of mammary gland development. The LIP isoform, however, is most readily detected during pregnancy, a period of rapid epithelial cell proliferation. The expression profile of the C/EBP $\beta$ isoforms is in part regulated by lactogenic hormones (e.g. glucocorticoids), and it reflects the importance of the isoforms in the expression of milk protein genes such as $\beta$ casein and whey acidic protein $[8,10,11]$.

\section{C/EBP $\alpha$ gene}

$C / E B P \alpha$ is not as widely expressed as $C / E B P \beta$, and is detected in the liver, adipose tissue, the mammary gland, the lung, the intestine, the adrenal gland, the placenta, and peripheral blood mononuclear cells. The intronless $C / E B P \alpha$ gene encodes a $2.7 \mathrm{~kb}$ mRNA that is translated into 42 and $30 \mathrm{kDa}$ isoforms via a leaky ribosome scanning mechanism [6]. As was observed for C/EBP $\beta$-LIP, the truncated $30 \mathrm{kDa}$ isoform of C/EBP $\alpha$ is not as potent a transactivator of gene expression as the full-length $42 \mathrm{kDa}$ isoform $[12,13]$.

\section{C/EBP $\alpha$ mRNA}

Reports on the expression profile for C/EBP $\alpha$ in the mammary gland are not in complete agreement. Some data suggest that $C / E B P \alpha$ levels are the most easily detected in the virgin gland, but are generally low and remain unchanged throughout mouse mammary gland development $[9,14]$. It has also been hypothesized that the low level of expression observed for C/EBP $\alpha$ mRNA during lactation is the result of a dilutional effect from overly abundant milk protein RNAs [9]. Other workers have demonstrated that $C / E B P \alpha \mathrm{mRNA}$ is high during the early stages of lactation, expressed at lower levels during the late stages of lactation/early involution, and increases again during late involution [15]. It is consequently uncertain whether the cascade model of C/EBP regulation, which has been proposed in adipocyte differentiation and which results in activation of $C / E B P \alpha$ by $C / E B P \beta$ and $C / E B P \delta[16]$, occurs in the mammary gland.

\section{C/EBP $\alpha$ protein}

Few studies have examined C/EBP $\alpha$ protein expression during mammary development. Raught et al. demonstrated that the $42 \mathrm{kDa}$ protein isoform is expressed at high levels during lactation and at lower levels during involution in the rat mammary gland [8].

\section{C/EBP $\delta$ gene}

This intronless gene is transcribed as a single mRNA $(1.2 \mathrm{~kb})$ that encodes a 269 amino acid protein and is expressed in the intestine, adipose tissue, the lung and the mammary gland. The DNA binding affinity of $C / E B P \delta$ is less than that for $C / E B P \beta$ and $C / E B P \alpha$, but the transactivation potentials are comparable [17]. The expression of $C / E B P \delta$ mRNA during mammary development is different from that reported for the protein. The reasons for this discrepancy are unclear.

\section{C/EBP $\delta$ MRNA}

$C / E B P \delta$ expression is low throughout pregnancy and lactation, but it increases dramatically ( $>100$-fold) within the first 12 hours of involution. This precedes the induction of $C / E B P \beta$ at $24-48$ hours [7].

\section{C/EBP $\delta$ protein}

Developmental expression of C/EBP $\delta$ protein in the rat mammary gland mimics that of C/EBP $\beta$ protein. Low expression levels are present in the virgin/involuted gland, with the highest levels observed during pregnancy, followed by a decrease in expression during early lactation and an increase in expression towards late lactation [8].

\section{Knockout mice: invaluable tools in the analysis of mammary gland development}

Targeted gene deletions have proven to be an invaluable tool in the analysis of mammary gland development. Unfortunately, some gene deletions result in a lethal phenotype. 
The mouse mammary gland provides a unique system in which these lethal phenotypes can be rescued and analyzed. The mammary fat pad, when cleared of endogenous epithelial cells, is an ideal site for the transplantation and analysis of tissue from mice that die embryonically or as neonates. Additionally, transplantation studies permit the analysis of epithelial-stromal interactions between tissues of different genetic backgrounds, as observed in studies with the $C / E B P \alpha$ and $C / E B P \beta$ knockout mice and as discussed in the following.

\section{C/EBP $\beta$ knockout mice}

$C / E B P \beta$-deficient mice were generated by two independent groups in 1995 [18,19], and were found to have defects in mammary gland development. Mammary glands from $C / E B P \beta^{-1-}$ virgin mice exhibited delayed ductal outgrowth, distended ducts and decreased branching $[9,14]$. The abnormal ductal morphogenesis in the virgin gland was in part due to a lack of normal ovarian function in the $C / E B P \beta^{-1-}$ mice, and could be partially rescued using wild-type ovarian transplants and treatment with estradiol and progesterone. The proliferative rate, the lobuloalveolar development, and the expression of milk proteins, $\beta$-casein and whey acidic protein, were dramatically inhibited in the $C / E B P \beta^{-1-}$ mouse despite hormone replacement $[9,14]$. An elegant series of transplantation experiments were conducted by both these groups to test whether the impairment in ductal morphogenesis and lobuloalveolar development was intrinsic to the epithelial cells or was mediated via stromal and systemic interactions. $C / E B P \beta^{-1-}$, $C / E B P \beta^{-/+}$, or $C / E B P \beta^{+/+}$epithelia were transplanted into wild-type stroma $\left(C / E B P \beta^{++}\right)$of either host nude mice or syngeneic mice that had been 'cleared' of endogenous epithelial cells. In the reverse experiment, $C / E B P \beta^{+/+}$donor epithelia were transplanted into the cleared stroma of $C / E B P \beta^{-1-}$ mice. Both types of transplantation experiments demonstrated that the defects in ductal morphogenesis and in lobuloalveolar development were due to the loss of $C / E B P \beta$ in the epithelia and were not a result of defects in stromal signaling that may occur due to $C / E B P \beta$ deficiency $[9,14]$. In conclusion, the C/EBP $\beta$ knockout mouse has proven a useful model in determining that $C / E B P \beta$ is critical for mammary gland development.

\section{C/EBP $\alpha$ knockout mice}

Mice deficient for C/EBP $\alpha$ were also developed in 1995. Studies of mice homozygous for the targeted deletion are limited, however, because $C / E B P \alpha$ knockout mice die within 8 hours of birth due to the defective induction of liver enzymes essential for glucose metabolism [20]. The analysis of mammary gland development in C/EBP $\alpha^{-1-}$ mice was consequently possible only via transplantation experiments. Seagroves et al. transplanted neonatal mammary anlagen into the cleared fat pads of syngeneic hosts and conducted subsequent serial transplantation of fat pads of additional syngeneic hosts [9]. On whole mount analysis of the second generation tissue, no differences in mammary development were detected between the $\mathrm{C} / E B P \alpha^{+/+}$or $C / E B P \alpha^{-1-}$ transplanted glands in virgin, pregnant, lactating or involuted mice [9]. These experiments demonstrate that although $C / E B P \alpha$ is expressed in mammary epithelial cells, the deletion of this gene does not affect normal mammary gland development.

\section{C/EBP $\beta$ C/EBP $\delta$ double knockout mice}

$C / E B P \delta^{-1-}$ mice are viable, fertile and, it is assumed, could lactate and nurse their pups because no mammary gland abnormalities have been reported [21]. In contrast, $85 \%$ of $C / E B P \beta^{-1-} C / E B P \delta^{--}$double knockout mice died at the perinatal or early postnatal stage. No gross abnormalities were observed in the surviving neonates, but the mice exhibited defective adipocyte differentiation [21]. No mammary gland abnormalities have been reported for these double knockout mice, and it is unknown whether the gland has been analyzed for defects in development.

\section{C/EBPs in mouse mammary gland tumors}

The expression profile of the C/EBPs during mammary development suggested that $C / E B P \beta$ is more involved in the control of cellular proliferation than the other C/EBP family members. Previous data in adipocytes [22], in hepatocytes [23], and in regenerating liver [24] have also supported a role for $C / E B P \beta$ in the control of proliferation.

It was hypothesized that the expression of $C / E B P \beta$ would be elevated in situations of uncontrolled proliferation such as tumorigenesis. C/EBP $\beta$ expression was consequently analyzed in mammary gland tumors from different transgenic mouse models as well as in nontumorigenic, hyperplastic outgrowths. The C/EBP $\beta$-LAP isoform was observed in whole cell extracts from both tumors and nontumorigenic hyperplastic outgrowths. The LIP isoform, however, was only detectable in tumor extracts [25].

In summary, C/EBP $\beta$-LIP was overexpressed in rodent mammary tumors, but not in nontumorigenic hyperplastic mouse outgrowths. Similar results at the transcriptional level have been observed in mammary tumors from MMTV/c-neu transgenic mice. C/EBP $\beta$ mRNA expression was found to be elevated in $100 \%$ of mammary tumors isolated from these ErbB2 overexpressing mice and, interestingly, $C / E B P \alpha$ mRNA was detected at low levels in $30 \%$ of tumors, C/EBP $\delta$ mRNA was detected at variable levels in $50 \%$ of the tumors, and CHOP mRNA was detectable in most of the tumors examined [26].

\section{C/EBPs in human breast cancer specimens}

The data from these studies suggested that $C / E B P \beta$ plays a role in tumorigenesis of the rodent mammary gland, but it was unknown what role this factor may have in human breast cancer. Our laboratory addressed this question by 
analyzing $C / E B P \beta$ expression levels in infiltrating ductal carcinoma specimens from 39 women. Both C/EBP $\beta$-LAP and C/EBP $\beta$-LIP were expressed in approximately $70 \%$ of the tumor extracts examined by western blot analysis. However, LIP was expressed at high levels (approximately 15 times higher than the levels of LIP in the lower expressing or nonexpressing tumors) in $23 \%$ of the infiltrating ductal carcinomas. High levels of LIP were associated with tumors that were estrogen-negative and progesterone receptor-negative, were aneuploid, were highly proliferative, and were poorly differentiated (classified as Elston-Ellis grade III) [27]. Other researchers have observed LIP expression in cultured breast cancer cells as well as in normal human mammary epithelial cells, and have demonstrated that LAP $(55 \mathrm{kDa})$ is found exclusively in normal mammary cells but that LAP $(46 \mathrm{kDa})$ is restricted to dividing cells (both normal and neoplastic) [5].

Breast cancer is commonly surrounded by desmoplasia, which is an accumulation of fibroblasts that provides structural and biochemical support for the tumor. It is believed that the malignant epithelial cells secrete factors that prevent the differentiation of the stromal fibroblasts to adipocytes. It has recently been demonstrated that epithelial, breast tumor-derived cytokines can act on the stroma to cause downregulation of $C / E B P \alpha$, and act on the peroxisome proliferator activated receptor $\gamma$ to cause the upregulation of $C / E B P \beta$ and $C / E B P \delta$ [28]. This increase in $C / E B P \beta$ expression can then mediate aromatase overexpression in the adipose fibroblasts, which in turn increases the formation of estrogens and stimulates the proliferation of the epithelial cells [29].

Although not discussed extensively in the present review, CHOP has been shown via RT-PCR to be overexpressed in breast tumor specimens [30]. CHOP can also be induced in human breast cell lines by glutamine deprivation [31].

These observations are consistent with the hypothesis that the $C / E B P \beta$ isoforms are important for differentiation and proliferation in the mammary gland. However, these studies did not directly address the question of whether overexpression of LIP or LAP is a consequence of proliferative, uncontrolled growth or whether it actually contributes to tumor development. These types of functionality studies have been best addressed using transgenic mice and overexpression in cell culture.

\section{Functionality studies: a role for $C / E B P \beta$ in breast cancer C/EBP $\beta$-LIP transgenic mice}

Little is known about how the LAP and LIP isoforms independently regulate cell-cycle progression in the intact mammary gland. Unfortunately, only one transgenic mouse study has been published to date that investigates the functional significance of overexpression of the $C / E B P \beta$ isoforms in the mammary gland [32]. Likewise, no transgenic mice have been generated that overexpress either $C / E B P \alpha$ or $C / E B P \delta$ in the mammary gland.

C/EBP $\beta$-LIP was overexpressed in the mouse mammary gland under the control of whey acidic protein sequences that preferentially target expression to the mouse mammary gland at day 10 of pregnancy, extending throughout lactation [32,33]. Mammary gland abnormalities were detected in the involuted glands of multiparous, aged females. These abnormalities included focal and diffuse hyperplasia in $30-40 \%$ of the glands examined and, less frequently, mammary intraepithelial neoplasias (similar to ductal carcinoma in situ) and invasive and noninvasive carcinomas in $9 \%$ of the glands [32]. These results demonstrated that overexpression of LIP itself was not sufficient to induce tumorigenesis. Elevated LIP expression can, however, induce proliferation and hyperplasias that may be more susceptible to additional oncogenic hits.

\section{Cell culture overexpression studies $\mathrm{C} / \mathrm{EBP} \beta$ gene}

The effects of overexpression of either C/EBP $\beta$-LAP or $\mathrm{C} / \mathrm{EBP} \beta$-LIP on cell-cycle progression and growth rate have been analyzed in many different cell lines, but have recently been examined in immortalized mammary epithelial cells. A study in the HC11 mouse mammary epithelial cell line demonstrated that growth rate, as observed over a 72-hour period, was relatively unaffected by the overexpression of either LIP or LAP [26].

Likewise, our laboratory stably transfected and overexpressed the C/EBP $\beta$-LIP isoform in the TM3 mouse mammary epithelial cell line [32]. We also observed that cells stably expressing LIP did not show abnormalities in the growth rate during exponential growth, but on reaching confluence (day 7 of culture) some of the cells had escaped contact inhibition and, by day 15 of culture, at least $10 \%$ of the cells had re-entered the cell cycle and were forming proliferative foci [32]. The proliferative effects of LIP overexpression observed in cell culture were reproduced on transplantation of LIP-expressing TM3 cells into the cleared fat pad of syngeneic mice [32].

Similar results have been demonstrated during the differentiation of 3T3-L1 adipocytes [34]. LIP was stably introduced via retroviral gene transfer, and adipogenesis was induced by standard methods. Cells were examined at day 8 of differentiation and it was observed that LIP overexpression resulted in foci formation and a loss of contact inhibition, as well as the prevention of terminal adipogenic differentiation and the induction of a transformed phenotype [34].

Unfortunately, with the exception of the study by Dearth et al. [26], most studies of LAP overexpression have been 
conducted in nonmammary cells. These experiments have demonstrated that LAP induces differentiation and/or cellcycle arrest in hepatocytes [23], in hematopoietic cells [35], and in adipocytes [36].

It is clear that additional studies need to be conducted in mammary epithelial cells to conclusively determine whether LIP and LAP have opposing and/or overlapping actions on growth during normal mammary gland development and breast cancer.

\section{C/EBP $\delta$ gene}

It has been demonstrated that $C / E B P \delta$ can regulate $\mathrm{G}_{0}$ growth arrest and apoptosis in $\mathrm{HC} 11$ mammary epithelial cells [37]. Under optimal growth conditions, C/EBP $\delta$ does not influence growth rate. In suboptimal growth conditions, however, reduction of $C / E B P \delta$ via antisense methodology increased proliferation, and overexpression of $C / E B P \delta$ decreased proliferation via a $\mathrm{G}_{0}$ growth arrest mechanism [37].

\section{The ratio of full-length/truncated C/EBP isoforms and the control of cell fate}

Changes in the ratio of the C/EBP $\beta$ isoforms LAP/LIP have been observed in mammary gland development $[8,9]$, in breast cancer [5,27], in ovarian cancer [38], in colorectal cancer [39], in liver development [40], and in inductive processes such as liver regeneration [41] and the lipopolysaccharide-mediated acute phase response [42]. The general observation is that LIP levels are increased in the more proliferative tumors or proliferative developmental time points. For example, LAP expression is detected in many breast cancer specimens, but the LIP isoform is more highly expressed in the most aggressive, poorly differentiated cancers [27]. Likewise, LAP is present at low levels in the normal postmenopausal ovary and associated benign tumors, but LAP expression increases in malignant samples, while the LIP isoform is only detected in the malignant tissues [38]. Similarly, LAP expression is increased in colon cancer, but the LIP isoform is expressed at higher levels in the more invasive Duke's stage B tumors as compared with the less invasive Duke's stage A tumors [39].

On a similar note, $\mathrm{N}$-terminal mutations of $C / E B P \alpha$ have been identified in patients with acute myeloid leukemia [43]. These mutations produce a truncated full-length protein $(20 \mathrm{kDa})$ that enhances the alternative translation of the $30 \mathrm{kDa}$ isoform. The mutant proteins $(20 \mathrm{kDa})$ and the $30 \mathrm{kDa}$ isoform act as dominant negatives and block the trans-activation potential of the wild-type, full-length isoform $(42 \mathrm{kDa})$ [43].

In view of the fact that the ratio of full-length/truncated isoforms appears to be important in the control of cell fate, it is important to consider the mechanisms that have been

\section{Proteolytic generation of the LAP/LIP ratio}

Both in vivo proteolysis and in vitro proteolysis via a calpain protease have been proposed as mechanisms to generate the LIP isoform. Specific in vivo proteolytic cleavage of full-length $C / E B P \beta$ has been shown to occur in prenatal and neonatal mouse liver, and is dependent on $C / E B P \alpha$ expression [44]. Other groups have reported that artifactual in vitro proteolytic cleavage of $C / E B P \beta$ can occur and is dependent on the cell lysis procedure $[26,45]$.

It has been suggested that mixing of the cytoplasmic and nuclear compartments could expose the nuclear C/EBP $\beta$ to cytoplasmic proteases or could activate nuclear, calcium-dependent proteases via cytoplasmic calcium [45]. Interestingly, Baer and Johnson also demonstrated that proteolytic cleavage of LIP was dependent on the presence of the leucine zipper region, and suggested that dimerization could alter the protein's folded structure and render it more susceptible to proteolysis [45].

\section{Translational control of the LAP/LIP ratio}

Translational control of C/EBP isoform expression has been most thoroughly studied in $C / E B P \alpha$ and $C / E B P \beta$. Because $C / E B P \alpha$ does not play a critical role in mammary development or breast cancer, the present review will emphasize the translational regulation of $C / E B P \beta$.

Translation of mRNA can be regulated by AUG codons within transcript leaders, referred to as upstream AUGs, and associated upstream open reading frames (uORFs) [46]. Upstream AUGs are commonly associated with oncogenes and genes that regulate cellular growth and differentiation [46]. C/EBP $\beta$ mRNA contains an out-of-frame uORF that codes for a short, nine amino acid peptide located between the LAP1 and the LAP2 translation start sites [25]. It has been hypothesized that both the LAP1 and the LAP2 translation start sites, as well as the UORF, are embedded within a stem loop structure that may play an important role in the regulation of AUG recognition [25] (Fig. 1).

Several different mechanisms have been described to account for the differential expression of the C/EBP $\beta$ isoforms. A leaky ribosome scanning mechanism was initially proposed to give rise to translational initiation at alternate AUG codons [6]. It was suggested that if a leaky ribosome scanning complex were to translate the uORF, it may favor reinitiation further downstream at the LIP AUG codon, which is positioned within a perfect Kozak consensus sequence (see Fig. 1) [25,46]. However, Lincoln et al. have found that the uORF does not facilitate translation of the LIP isoform [47].

The laboratory of Leutz recently conducted an elegant study to address the controversies surrounding the role of the uORF in translational regulation of the LIP isoform versus the proposed mechanism of proteolytic cleavage to generate LIP 
[34]. Strong evidence was presented to support the hypothesis that the $C / E B P \beta$ isoforms arise via differential usage of translation start sites rather than by proteolysis. Leutz and coworkers showed that translation of the LIP isoform in cultured cells is strictly regulated by the UORF, but translation of LAP can occur either by leaky ribosome scanning or by reinitiation of ribosomes immediately after translation of the uORF [34]. Interestingly, increased levels of elF-4E and elF2 favor LIP translation and function through associations with the uORF (Fig. 1) [34]. Both elF-2 [25] and elF-4E [48] are overexpressed in breast cancer and support our observation of increased LIP translation in human tumors.

The final translational mechanism is centered around a number of recent observations suggesting that LIP translation may be controlled by specific RNA binding proteins that interact with the $5^{\prime}$ region of C/EBP $\beta$ mRNA [49]. One of these proteins, the CUG triplet repeat binding protein (CUGBP1), has been characterized in detail. CUGBP1 binds to the CCG repeat located within the uORF of C/EBP $\beta$ mRNA [49]. The binding of CUGBP1 to the $5^{\prime}$ region of $C / E B P \beta$ mRNA induces the translation of the LIP isoform in rat and mouse liver during the acute phase response, and in cell-free translation systems $[49,50]$. These observations suggest that the production of the dominant-negative LIP isoform can be controlled at different levels through several mechanisms.

\section{Regulation of $C / E B P \beta$ activity by phosphorylation and protein-protein interactions}

In addition to translational regulation of the LAP/LIP ratio, post-translational phosphorylation and protein-protein interactions have been shown to regulate the transcriptional activity and the DNA binding activity of $C / E B P \beta$. Although most of these studies were not conducted in mammary tissue, many of the observations may be valid and worthy of investigation in breast development or breast cancer. Phosphorylation of Ser276 by $\mathrm{Ca}^{2+}$. calmodulin-dependent kinases in pituitary G/C cells has been shown to stimulate the transcriptional activity of $C / E B P \beta$ [51]. However, phosphorylation of Ser299 by protein kinase $C$ in rat liver attenuates DNA binding [52]. Additionally, phosphorylation by a ras-dependent mitogenactivated protein kinase cascade at Thr235 in NIH 3 T3 fibroblasts and in embryonic carcinoma P19 cells stimulates the transciptional activity of human C/EBP $\beta$ (NF-IL6) [53]. Also, phosphorylation of rat Ser105 or mouse Thr217 in response to stimulators of cell proliferation such as phorbol esters and growth factors (transforming growth factor alpha) occurs via the protein kinase $C$ and the p90 ribosomal $\mathrm{S}$ kinase pathways, and enhances the transactivation of target genes $[54,55]$.

Phosphorylation has also been shown to affect the subcellular distribution of $C / E B P \beta$. When overexpressed in a mouse model or added to cultures of primary mouse hepatocytes, tumor necrosis factor alpha induces the phosphorylation of Ser239 and the consequent nuclear export of $C / E B P \beta$, thereby preventing transcription of the albumin gene [56]. However, osteoprotegerin ligand (which is a member of the tumor necrosis factor superfamily) is believed to facilitate nuclear import of $C / E B P \beta$ in the mouse mammary epithelial cell line (HC11) and in mouse primary mammary epithelial cells, thus allowing for the transcriptional activation of $\beta$-casein [57].

Increasing evidence suggests that the C/EBPs are also capable of protein-protein interactions with regulators of cell-cycle progression or cell development, such as retinoblastoma [58,59], Cdk2 and Cdk4 [60], NF-kB-p50 [61] and glucocorticoid receptor [62].

\section{Conclusions}

Of the six C/EBP genes, only C/EBP $\beta$ and $C / E B P \delta$ have conclusive actions in the mammary gland. C/EBP appears to be most important for growth arrest and apoptosis, whereas $C / E B P \beta$ is necessary for growth and differentiation.

The functional analysis of $C / E B P \beta$ is made more complicated by the presence of the LIP and LAP isoforms, which may have opposing actions on growth and are not always expressed as a $1: 1$ ratio. Although $C / E B P \delta$ is variably expressed in breast cancer specimens, a role in tumorigenesis has not been demonstrated. Both LAP and LIP are overexpressed in breast cancer, but LIP is often more highly expressed in the more proliferative and aggressive tumors. Likewise, the LIP isoform can induce cellular proliferation when overexpressed in mouse mammary glands or in cultured cells.

It is clear that additional studies need to be conducted to address the translational and proteolytic regulation of LIP/LAP, as well as to dissect out the individual functions and role that LIP and LAP play in breast cancer. However, these experiments are inherently difficult to conduct and interpret for several reasons. First, endogenous $C / E B P \alpha$, $C / E B P \beta, C / E B P \delta$ and $C / E B P \zeta(C H O P)$ may be present in mammary cells and may be capable of interacting with LIP and LAP. Second, better antibodies need to be generated that can selectively recognize only the LIP or LAP isoform in immunohistochemical applications. Protein extraction and western blotting could then be avoided, which would perhaps resolve some of the controversies associated with the translational versus in vitro proteolytic generation of C/EBP $\beta$-LIP.

\section{Acknowledgements}

Research on this topic was supported by a new investigator $\mathrm{NCl} P 30$ award, an ACS IRG 58-005-40 award, a P50 CA88843 career development award, and a grant from the US Army Breast Cancer Research Program DAMD17-01-1-0287. The author is grateful to Dr Jeffrey Rosen and Dr Nikolai Timchenko for helpful comments. 


\section{References}

1. Lekstrom-Himes J, Xanthopoulos KG: Biological role of the CCAAT/enhancer-binding protein family of transcription factors. J Biol Chem 1998, 273:28545-28548.

2. Landschulz WH, Johnson PF, McKnight SL: The DNA binding domain of the rat liver nuclear protein C/EBP is bipartite. Science 1989, 243:1681-1688.

3. Patel LR, Curran T, Kerppola TK: Energy transfer analysis of Fos-Jun dimerization and DNA binding. Proc Natl Acad Sci USA 1994, 91:7360-7364.

4. Vinson CR, Sigler PB, McKnight SL: Scissors-grip model for DNA recognition by a family of leucine zipper proteins. Science 1989, 246:911-916.

5. Eaton EM, Hanlon M, Bundy L, Sealy L: Characterization of $\mathrm{C} / \mathrm{EBPbeta}$ isoforms in normal versus neoplastic mammary epithelial cells. J Cell Physiol 2001, 189:91-105.

6. Descombes $\mathrm{P}$, Schibler U: A liver-enriched transcriptional activator protein, LAP, and a transcriptional inhibitory protein, LIP, are translated from the same mRNA. Cell 1991, 67:569-579.

7. Gigliotti AP, DeWille JW: Lactation status influences expression of CCAAT/enhancer binding protein isoform mRNA in the mouse mammary gland. J Cell Physiol 1998, 174:232-239.

8. Raught B, Liao WS, Rosen JM: Developmentally and hormonally regulated CCAAT/enhancer-binding protein isoforms influence beta-casein gene expression. Mol Endocrinol 1995, 9:1223-1232

9. Seagroves TN, Krnacik S, Raught B, Gay J, Burgess-Beusse B, Darlington GJ, Rosen JM: C/EBPbeta, but not C/EBPalpha, is essential for ductal morphogenesis, lobuloalveolar proliferation, and functional differentiation in the mouse mammary gland. Genes Dev 1998, 12:1917-1928.

10. Rosen JM, Zahnow C, Kazansky A, Raught B: Composite response elements mediate hormonal and developmental regulation of milk protein gene expression. Biochem Soc Symp 1998, 63:101-113.

11. Wyszomierski SL, Rosen JM: Cooperative effects of STAT5 (signal transducer and activator of transcription 5) and C/EBPbeta (CCAAT/enhancer-binding protein-beta) on betacasein gene transcription are mediated by the glucocorticoid receptor. Mol Endocrinol 2001, 15:228-240.

12. Ossipow V, Descombes P, Schibler U: CCAAT/enhancerbinding protein mRNA is translated into multiple proteins with different transcription activation potentials. Proc Natl Acad Sci USA 1993, 90:8219-8223.

13. Lin FT, MacDougald OA, Diehl AM, Lane MD: A 30-kDa alternative translation product of the CCAAT/enhancer binding protein alpha message: transcriptional activator lacking antimitotic activity. Proc Natl Acad Sci USA 1993, 90:9606-9610.

14. Robinson GW, Johnson PF, Hennighausen L, Sterneck E: The $\mathrm{C} / \mathrm{EBPb}$ ta transcription factor regulates epithelial cell proliferation and differentiation in the mammary gland. Genes Dev 1998, 12:1907-1916.

15. Sabatakos G, Davies GE, Grosse M, Cryer A, Ramji DP: Expression of the genes encoding CCAAT-enhancer binding protein isoforms in the mouse mammary gland during lactation and involution. Biochem J 1998, 334(part 1):205-210.

16. Yeh WC, Cao Z, Classon M, McKnight SL: Cascade regulation of terminal adipocyte differentiation by three members of the C/EBP family of leucine zipper proteins. Genes Dev 1995, 9: 168-181.

17. Cao Z, Umek RM, McKnight SL: Regulated expression of three C/EBP isoforms during adipose conversion of 3T3-L1 cells. Genes Dev 1991, 5:1538-1552.

18. Screpanti I, Romani L, Musiani P, Modesti A, Fattori E, Lazzaro D, Sellitto C, Scarpa S, Bellavia D, Lattanzio G, Bistoni F, Frati L, Cortese R, Gulino A, Ciliberto G, Costantini F, Poli V: Lymphoproliferative disorder and imbalanced $\mathrm{T}$-helper response in C/EBP beta-deficient mice. EMBO J 1995, 14:1932-1941.

19. Tanaka T, Akira S, Yoshida K, Umemoto M, Yoneda Y, Shirafuji N, Fujiwara H, Suematsu S, Yoshida N, Kisimoto T: Targeted disruption of the NF-IL6 gene discloses its essential role in bacteria killing and tumor cytotoxicity by macrophages. Cell 1995, 80:353-361.

20. Wang ND, Finegold MJ, Bradley A, Ou CN, Abdelsayed SV, Wilde MD, Taylor LR, Wilson DR, Darlington GJ: Impaired energy homeostasis in C/EBP alpha knockout mice. Science 1995, 269:1108-1112.
21. Tanaka T, Yoshida N, Kishimoto T, Akira S: Defective adipocyte differentiation in mice lacking the C/EBPbeta and/or C/EBPdelta gene. EMBO J 1997, 16:7432-7443.

22. Christy RJ, Kaestner KH, Geiman DE, Lane MD: CCAAT/ enhancer binding protein gene promoter: binding of nuclear factors during differentiation of 3T3-L1 preadipocytes. Proc Natl Acad Sci USA 1991, 88:2593-2597.

23. Buck M, Turler H, Chojkier M: LAP (NF-IL-6), a tissue-specific transcriptional activator, is an inhibitor of hepatoma cell proliferation. EMBO J 1994, 13:851-860

24. Greenbaum LE, Li W, Cressman DE, Peng Y, Ciliberto G, Poli V, Taub R: CCAAT enhancer-binding protein beta is required for normal hepatocyte proliferation in mice after partial hepatectomy. J Clin Invest 1998, 102:996-1007.

25. Raught B, Gingras AC, James A, Medina D, Sonenberg N, Rosen JM: Expression of a translationally regulated, dominant-negative CCAAT/enhancer-binding protein beta isoform and upregulation of the eukaryotic translation initiation factor 2alpha are correlated with neoplastic transformation of mammary epithelial cells. Cancer Res 1996, 56:4382-4386.

26. Dearth LR, Hutt J, Sattler A, Gigliotti A, DeWille J: Expression and function of CCAAT/enhancer binding proteinbeta (C/EBPbeta) LAP and LIP isoforms in mouse mammary gland, tumors and cultured mammary epithelial cells. J Cell Biochem 2001, 82:357-370.

27. Zahnow CA, Younes $P$, Laucirica R, Rosen JM: Overexpression of C/EBPbeta-LIP, a naturally occurring, dominant-negative transcription factor, in human breast cancer. J Natl Cancer Inst 1997, 89:1887-1891.

28. Meng L, Zhou J, Sasano H, Suzuki T, Zeitoun KM, Bulun SE: Tumor necrosis factor alpha and interleukin 11 secreted by malignant breast epithelial cells inhibit adipocyte differentiation by selectively down-regulating CCAAT/enhancer binding protein alpha and peroxisome proliferator-activated receptor gamma: mechanism of desmoplastic reaction. Cancer Res 2001, 61:2250-2255.

29. Zhou J, Gurates B, Yang S, Sebastian S, Bulun SE: Malignant breast epithelial cells stimulate aromatase expression via promoter II in human adipose fibroblasts: an epithelial-stromal interaction in breast tumors mediated by CCAAT/enhancer binding protein beta. Cancer Res 2001, 61:2328-2334.

30. Arnal M, Solary E, Brunet-Lecomte P, Lizard-Nacol S: Expression of the gadd153 gene in normal and tumor breast tissues by a sensitive RT-PCR method. Int J Mol Med 1999, 4:545-548.

31. Abcouwer SF, Schwarz C, Meguid RA: Glutamine deprivation induces the expression of GADD45 and GADD153 primarily by mRNA stabilization. J Biol Chem 1999, 274:28645-28651.

32. Zahnow CA, Cardiff RD, Laucirica R, Medina D, Rosen JM: A role for CCAAT/enhancer binding protein beta-liver-enriched inhibitory protein in mammary epithelial cell proliferation. Cancer Res 2001, 61:261-269.

33. Bayna EM, Rosen JM: Tissue-specific, high level expression of the rat whey acidic protein gene in transgenic mice. Nucleic Acids Res 1990, 18:2977-2985.

34. Calkhoven CF, Muller C, Leutz A: Translational control of C/EBPalpha and C/EBPbeta isoform expression. Genes Dev 2000, 14:1920-1932.

35. Nerlov C, McNagny KM, Doderlein G, Kowenz-Leutz E, Graf T: Distinct C/EBP functions are required for eosinophil lineage commitment and maturation. Genes Dev 1998, 12:2413-2423.

36. Wu Z, Xie Y, Bucher NL, Farmer SR: Conditional ectopic expression of C/EBP beta in NIH-3T3 cells induces PPAR gamma and stimulates adipogenesis. Genes Dev 1995, 9:2350-2363.

37. O'Rourke JP, Newbound GC, Hutt JA, DeWille J: CCAAT/enhancer-binding protein delta regulates mammary epithelial cell GO growth arrest and apoptosis. J Biol Chem 1999, 274:16582-16589.

38. Sundfeldt K, Ivarsson K, Carlsson M, Enerback S, Janson PO, Brannstrom M, Hedin L: The expression of CCAAT/enhancer binding protein $(C / E B P)$ in the human ovary in vivo: specific increase in $\mathrm{C} / \mathrm{EBPbeta}$ during epithelial tumour progression. Br J Cancer 1999, 79:1240-1248.

39. Rask K, Thorn M, Ponten F, Kraaz W, Sundfeldt K, Hedin L, Enerback $S$ : Increased expression of the transcription factors CCAAT-enhancer binding protein-beta (C/EBBeta) and $\mathrm{C} / \mathrm{EBzeta}$ (CHOP) correlate with invasiveness of human colorectal cancer. Int J Cancer 2000, 86:337-343. 
40. Diehl AM, Michaelson $P$, Yang SQ: Selective induction of CCAAT/enhancer binding protein isoforms occurs during rat liver development. Gastroenterology 1994, 106:1625-1637.

41. Timchenko NA, Wilde M, Kosai KI, Heydari A, Bilyeu TA, Finegold MJ, Mohamedali K, Richardson A, Darlington GJ: Regenerating livers of old rats contain high levels of C/EBPalpha that correlate with altered expression of cell cycle associated proteins. Nucleic Acids Res 1998, 26:3293-3299.

42. An MR, Hsieh CC, Reisner PD, Rabek JP, Scott SG, Kuninger DT, Papaconstantinou J: Evidence for posttranscriptional regulation of $\mathrm{C} / \mathrm{EBPalpha}$ and $\mathrm{C} / \mathrm{EBPbeta}$ isoform expression during the lipopolysaccharide-mediated acute-phase response. Mol Cell Biol 1996, 16:2295-2306.

43. Pabst $T$, Mueller BU, Zhang $P$, Radomska HS, Narravula $S$, Schnittger S, Behre G, Hiddemann W, Tenen DG: Dominantnegative mutations of CEBPA, encoding CCAAT/enhancer binding protein-alpha (C/EBPalpha), in acute myeloid leukemia. Nat Genet 2001, 27:263-270.

44. Welm AL, Timchenko NA, Darlington GJ: C/EBPalpha regulates generation of C/EBPbeta isoforms through activation of specific proteolytic cleavage. Mol Cell Biol 1999, 19:1695-1704.

45. Baer M, Johnson PF: Generation of truncated C/EBPbeta isoforms by in vitro proteolysis. J Biol Chem 2000, 275:2658226590.

46. Morris DR, Geballe AP: Upstream open reading frames as regulators of mRNA translation. Mol Cell Biol 2000, 20:86358642.

47. Lincoln AJ, Monczak Y, Williams SC, Johnson PF: Inhibition of CCAAT/enhancer-binding protein alpha and beta translation by upstream open reading frames. J Biol Chem 1998, 273: 9552-9560.

48. De Benedetti A, Harris AL: elF4E expression in tumors: its possible role in progression of malignancies. Int $J$ Biochem Cell Biol 1999, 31:59-72.

49. Timchenko NA, Welm AL, Lu X, Timchenko LT: CUG repeat binding protein (CUGBP1) interacts with the $5^{\prime}$ region of $\mathrm{C} / \mathrm{EBPbeta} \mathrm{mRNA}$ and regulates translation of C/EBPbeta isoforms. Nucleic Acids Res 1999, 27:4517-4525.

50. Welm AL, Mackey SL, Timchenko LT, Darlington GJ, Timchenko NA: Translational induction of liver-enriched transcriptional inhibitory protein during acute phase response leads to repression of CCAAT/enhancer binding protein alpha mRNA. $J$ Biol Chem 2000, 275:27406-27413.

51. Wegner M, Cao Z, Rosenfeld MG: Calcium-regulated phosphorylation within the leucine zipper of C/EBP beta. Science 1992, 256:370-373.

52. Mahoney CW Shuman J, McKnight SL, Chen HC, Huang KP. Phosphorylation of CCAAT-enhancer binding protein by protein kinase $\mathbf{C}$ attenuates site-selective DNA binding. $J$ Biol Chem 1992, 267:19396-19403.

53. Nakajima T, Kinoshita S, Sasagawa T, Sasaki K, Naruto M, Kishimoto T, Akira S: Phosphorylation at threonine-235 by a rasdependent mitogen-activated protein kinase cascade is essential for transcription factor NF-IL6. Proc Natl Acad Sci USA 1993, 90:2207-2211.

54. Trautwein C, Caelles C, van der GP, Hunter T, Karin M, Chojkier M: Transactivation by NF-IL6/LAP is enhanced by phosphorylation of its activation domain. Nature 1993, 364:544-547.

55. Buck M, Poli V, van der GP, Chojkier M, Hunter T: Phosphorylation of rat serine 105 or mouse threonine 217 in C/EBP beta is required for hepatocyte proliferation induced by TGF alpha. Mol Cell 1999, 4:1087-1092.

56. Buck M, Zhang L, Halasz NA, Hunter T, Chojkier M: Nuclear export of phosphorylated C/EBPbeta mediates the inhibition of albumin expression by TNF-alpha. EMBO J 2001, 20:67126723.

57. Kim HJ, Yoon MJ, Lee J, Penninger JM, Kong YY: Osteoprotegerin ligand induces beta-casein gene expression through the transcription factor CCAAT/enhancer-binding protein beta. J Biol Chem 2002, 277:5339-5344.

58. Charles A, Tang X, Crouch E, Brody JS, Xiao ZX: Retinoblastoma protein complexes with C/EBP proteins and activates C/EBP-mediated transcription. J Cell Biochem 2001, 83:414425.

59. Chen PL, Riley DJ, Chen-Kiang S, Lee WH: Retinoblastoma protein directly interacts with and activates the transcription factor NF-IL6. Proc Natl Acad Sci USA 1996, 93:465-469.
60. Wang $H$, lakova P, Wilde M, Welm A, Goode T, Roesler WJ, Timchenko NA: C/EBPalpha arrests cell proliferation through direct inhibition of Cdk2 and Cdk4. Mol Cell 2001, 8:817-828.

61. LeClair KP, Blanar MA, Sharp PA: The p50 subunit of NF-kappa $B$ associates with the NF-IL6 transcription factor. Proc Nat Acad Sci USA 1992, 89:8145-8149.

62. Nishio $Y$, Isshiki $H$, Kishimoto $T$, Akira S: A nuclear factor for interleukin-6 expression (NF-IL6) and the glucocorticoid receptor synergistically activate transcription of the rat alpha 1 -acid glycoprotein gene via direct protein-protein interaction. Mol Cell Biol 1993, 13:1854-1862. 